\title{
Correction to: SGLT2 Inhibitors: Cardiovascular Benefits Beyond HbA1c-Translating Evidence into Practice
}

\author{
Amar Ali - Steve Bain - Debbie Hicks - Phillip Newland Jones · \\ Dipesh C. Patel · Marc Evans - Kevin Fernando · June James · \\ Nicola Milne $\cdot$ Adie Viljoen $\cdot$ John Wilding (1) · As part of The Improving Diabetes Steering Committee
}

Published online: July 18, 2019

(c) The Author(s) 2019

Correction to: Diabetes Ther

https://doi.org/10.1007/s13300-019-0657-8

In the original publication, Table 2 note was incorrectly published as "*SGLT2i therapies may be initiated in people with eGFR $60 \mathrm{~mL} / \mathrm{min} /$ $1.73 \mathrm{~m}^{2}$. Individuals already treated with canagliflozin or empagliflozin who demonstrate renal decline may continue treatment until eGFR reaches $<45 \mathrm{~mL} / \mathrm{min} / 1.73 \mathrm{~m}^{2 \prime}$.

The original article can be found online at https://doi. org/10.1007/s13300-019-0657-8.

A. Ali

Oakenhurst Medical Practice, Blackburn, UK

S. Bain

Diabetes Research Unit Cymru, Swansea University, Swansea, UK

D. Hicks

Medicus Health Partners, Enfield, UK

P. Newland Jones

University Hospitals Southampton NHS Foundation

Trust, Southampton, UK

D. C. Patel

Department of Diabetes and Endocrinology, Division of Medicine, University College London, London, UK

M. Evans

Department of Diabetes, University Hospital

Llandough, Llandough, UK
The correct text should read as "* SGLT2i therapies may be initiated in people with eGFR $60 \mathrm{~mL} / \mathrm{min} / 1.73 \mathrm{~m}^{2}$. Individuals already treated with an SGLT2i therapy who demonstrate renal decline may continue treatment until eGFR reaches $<45 \mathrm{~mL} / \mathrm{min} / 1.73 \mathrm{~m}^{2}$."

Open Access. This article is distributed under the terms of the Creative Commons Attribution-NonCommercial 4.0 International License (http://creativecommons.org/licenses/ by-nc/4.0/), which permits any noncommercial use, distribution, and reproduction in any

\section{K. Fernando}

North Berwick Health Centre, North Berwick, UK

J. James

University Hospitals of Leicester NHS Trust,

Leicester, UK

N. Milne

CODES (Community Diabetes Education and

Support), Manchester University NHS Foundation Trust, Manchester, UK

A. Viljoen

Department of Metabolic Medicine/Chemical Pathology, Lister Hospital, Stevenage, UK

J. Wilding $(\bowtie)$

Obesity and Endocrinology Research, University of

Liverpool, Liverpool, UK

e-mail: J.P.H.Wilding@liverpool.ac.uk 
medium, provided you give appropriate credit to the original author(s) and the source, provide a link to the Creative Commons license, and indicate if changes were made. 